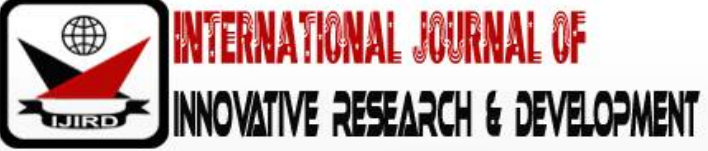

ISSN 2278 - 0211 (Online)

\section{Arab Children's Attitudes toward Companion Animalsin Israel}

\author{
Mohammad Hamad \\ Senior Lecturer, Department of Arabic language and Literature, Al-Qasemi College of Education, Israel \\ Saleh Kharanbeh \\ Lecturer, Department of Education and Society, Ohalo College of Education, Israel
}

\begin{abstract}
:
Many children develop empathy and positive attitudes toward animals, particularly domesticated pets. Some adopt a pet or companion animal. This article explores how these positive attitudes recreated, and the role of factors such as parents' education, socioeconomic status ( SES), gender, and age. It is hypothesizedthatpersonal experiences such as raising companion animals or creating emotional identification with animals through children's stories contribute to development of positive attitudes toward animals.

The study participants were 267 children, male and female, 7-9 years of age, randomly sampled from 25 Arabic language elementary schools in Israel. This is the first study conductedon this topic among this population. Participants responded toa questionnaireon the research topic and background variables.

The results confirm the hypotheses thatthere is a statistical correlation between being guardians forcompanion animals or reading stories about animals, and expressing positive attitudes toward companion animals, whileparents' education, SES, gender, and age have minor effects.
\end{abstract}

Keywords: Arab children, companion animals, pets,children's personal experience, reading stories, parent's education

\section{Introduction}

Many children develop empathy and positive attitudes towardanimals, especially domesticated pets or companion animals. Animals are considered an integral part of achild's world. Children may raise companion animalsat home. Theyobservenon-domesticated animals in their natural surroundings, on the computer, or on television. They visit zoos and petting farms. Some participate in educational activities involving animals, such as at wildlife reserves. First acquaintances with animals may occurat pre- and post-kindergarten ages. Childrenalso read and listen to stories featuring animals as characters, and study about them in school. This may be considered a different aspect of experience with animals.

\section{Theoretical Background and Literature Review}

There is a large body of research on the integration between children and pets, exploring various aspects, such as which animalsare most often adopted,what factors affect thedecision to adopt a companion animal, andwhat therapeutic benefits companion animals provide for children.Children and adults tend to have different motivations for raising companion animals in the home(Archer, 1997).

Various aspects of the interaction between animals and humans have been studied, such as the contribution of companion animals toward the psychosocial development of children and adolescents (Van Houtte, \& Jarvis, 1995). Research indicatesvaryinglevels of interaction between children and animals, considering theemotional, psychological, and social perspectives(Daly \& Morton, 2009; Kubiatko, 2012). These studies contribute to a detailed understanding of the role of animals in children's personal development, and provide cultural and clinical tools to nurture this development.

The interaction between animals and humans makes a significant therapeutic contribution to both parties. Caring for a companion animal is beneficialfor human health in the short-term and long-term (Wells, 2009). People enjoycompanion animals and benefit from the interaction socially and emotionally. For example, a companion animal can raise self-esteem and positive self-awareness, and reducedepression and loneliness (McConnell \& Brown, 2011).Clerks withcompanion animals at work demonstrate reduced tension levels and improved social interactions, compared with those who do not have companion animals(Wells \& Perrine, 2001).

However, a recent studyfindsthe beneficial impacts of dog therapy amongcollege students suffering from homesickness and stress aretemporary (Binfet\& Passmore, 2016). Nevertheless, thereis a long-termeffect onchildren who grow up with companion animals, which lasts into adulthood. In a study of Canadian students aged 18-21 years, those who had companion animals at home when they were children had lower levels of stress in their academic lives and greater 
social skills than students who had not raised companion animals as children (Daly \& Morton, 2009).Companion animals contribute to attitudes toward other animals. For example, a study conducted in Slovenia and Turkey finds that students who had a larger number ofcompanion animals in their childhood home had a lowerlevel of fear of snakes (Prokop, Özel, \&Usak, 2009).

In the Western world, companion animals are often considered part of the family. In one study among dog guardians, $48 \%$ of the participants said they consider their dogs to be family members; $67 \%$ were carrying a picture of their dog at the time of the survey; $73 \%$ allow the dog to sleep in their bedroom; and 40\% celebrate their dog's birthday (Archer, 1997). Similarly, a study conducted in Japan finds many guardians treat their companion animals, especially dogs and cats, as family members (Veldkamp, 2009). Some guardians even go so far as to bury their companion animals in special cemeteries, and grieve their deaths (Stallones, 1994). This is a characteristic of modern times, as families have become dispersed and couples have fewer children.

A survey of 400 companion animal guardians identifies friendship and a feeling of security as the major reasons for acquiring a companion animal (Lago, Kafer, Delaney, \&Connel, 1988). In a study of 737 people with dogs as companion animals, the majority says theyacquired dogs for the purpose of friendship (Jagoe\&Serpell, 1996). A study of 975 randomly selected participants from the USA, most of them (789)women, explores the types of relationships adults have with dogs. It finds that $36 \%$ of participants claim their dogs provide them with a safe haven; $39 \%$ consider them a basis for security, $61 \%$ cite proximity maintenance (staying close to companion animals for safety reasons); and $43 \%$ turn to them in times of distress. In fact, most participants said they prefer to turn to their dogs when they are distraught, rather thanturning to their mothers, fathers, brothers, sisters, or best friends (Kurdek, 2009).

Studies suggest that taking a companion animal into one's home promotes health. A study of 285 children aged 11-19 years in Slovenia, exploring the correlation between having companion animals and infectious diseases, finds that $58 \%$ of the child renhadcats or dogs as companion animals, and their close contact with them induced a protective response against infections, as compared to children not in close contact with companion animals (Prokop \& Fančovičová, 2011). According to Morley and Fook (2005), the primary benefits of companion animals relate to emotional and psychological health, promoting social interactions, and increasing the sense of responsibility.

Research on combinations of companion animals (i.e., cats, rabbits, hamsters, rats, turtles, frogs, birds, fish)in particular environments showsthat use of animals in California primary schools and kindergartens for teaching science and other fields, raises students' motivation to study (Zasloff\&Hart, 2000). It has been suggested that adding elementsto the formal educational curriculathat foster positive attitudes toward animals and an awareness of animal suffering from educational, environmental, and humanitarian viewpoints will encourage children to become teachers and policy-makers whocreate a better and more caring world (Pattnaik, 2004).

According to Raupp (1999), many parents are aware of the importance and strength of the interaction between companion animals and their children. Few (7.5\%)exploit this bond in negative ways, for example, to punish their children. It is worth noting that inhuman torture and exploitation ofanimals are important issues, but are seldom addressed in academic studies (Raupp, 1999; Stekette et al., 2011). Onestudy of people with high socioeconomic status (SES) revealsadark side of dog guardianship, in whichrare dog breeds with specific characteristics such as size or appearanceare acquired for prestige (Beverland, Farrelly, \&Ching Lim, 2007).

The other side of the relationshipconcernsthe animal. Many companion animals enjoy interaction with humans. Positive treatment byhumans leads to positivebehavior in the animal. A study of 737 people with dogsas companion animalsrevealsthat dogs are affected by their guardians' behavior toward them.Dogs' aggression levels decline when theirguardians treat them warmly, for example, allowing the dogsto sleep in their bedroom, or feeding the dogs around the same time as their guardians' meals (Jagoe\&Serpell, 1996). Another study showsthat as the level of connection increases between families and their dogs and cats, the animals' behaviorimprovesand they become more content, intelligent, and friendly. The animals losesome of their defensiveness and becomeless aggressive (Serpell, 1996).

\subsection{The Current Study}

\subsubsection{Research Aims}

This study focuses on attitudes toward companion animals among Arab children in Israel. It investigates how childrenperceivecompanion animals, as opposed to how adults view them. The research elucidates potential factors that create positive attitudes toward companion animals, including personal experiences with animals and reading books about animals. It considers the impact of traits such as parents'level of education, socioeconomic status, and the child's grade level and gender onattitudes towards companion animals and on choice ofcompanion animals currently in the home or that thechild would choose to adopt in the future.

\subsubsection{ResearchQuestions}

- To what extent do children's personal experiences with animals at home affect their stance toward companion animals?

- Does reading stories about animals affect the stances of children aged 7-9 years toward companion animals?

- Does gender affect choice of companion animalsamong 7- to 9-year-olds?

- Which companion animals do children prefer? 


\subsection{Study Hypotheses}

- H1: The more personal experiencesa7- to 9-year-old child has with companion animals, the more positive his/ her stance will be toward companion animals will be, comparedto children with less or no experience with companion animals.

- H2a: A child's stance toward companion animals will not be significantly affected by socioeconomic status, parents' education,orgender.

- H2b: The more stories the children read about animals, the more positive their stance toward animals will be,comparedto children who read few or no stories about animals.

- H3: Gender affects children's choice of the companion animal currently in the home, or which the child would choose to adopt in the future.

\section{Materials and Methods}

\subsection{Participations}

The study population included 267 children in first grade(138) or second grade(129). Their ages ranged from 7-9 years. They were randomly selected from 25 Arabic language elementary schools in the northern and Triangle1regionsof Israel. The study population was relatively equally balanced in terms of gender; 132 were maleand 135were female. All of children had siblings. Slightly over half of them (51.7\%) had three orfour siblings at home. Half their parents (50\%) had finished secondary school and a third (33.5\%) had completed higher education. The SES of most of thechildren's families was of amoderate (46.7\%) or high level (40.8\%). Almost all of the children's fathers were employed (97.4\%), and over half $(53.2 \%)$ of children's mothers had part-time jobs.

\subsection{Measures and Procedures}

The childrencompleted questionnaires with the assistance of their teachers. The teachers explained the aims of the study to the children, read the questions tothem, and explained the range of answers.

Children's attitudes.The tool to measure children's attitudes toward companion animals was designed specifically for this research (see Appendix), as we found no measurement tool for assessingthis issue in the literature.The research tool passed the reliability and validation pre-test conducted by three experts. Following this pre-test, some of the items were changed in accordance with the experts' comments. Thisversionof the questionnaire, with 25 items,was administeredto a pilot group of 30 children from two Arabic language schoolsin Israel'snorthern district. Based on this pilot test, the questionnaire was modified for the research population. This stage brought about a significant improvement in question formulation.

The questionnaire items include statements about attitudes towardcompanion animals such as: "A companion animal is useful for the house's residents." For each question, children rated their attitudes on a 3-point Likert scale ( 1 =disagree, 2 =agree, 3 =strongly agree).

The Cronbach's alpha coefficient for internal traceability to measure the reliability of the questionnaire was high, $\alpha=0.79$, indicating high grade stability. The scores for items $2,4,7,8,9,12$ and 17 , which contain negative statements about companion animals, were reversed so thatall of the items in the questionnaire represent positive attitudes.

Further, the questionnaire includesquestions about background variables such as grade in school, gender, parents' education, parents' employment, income, and number of siblings. It asks what type of companion animalcurrently lives in the home or, if the home has no companion animal, which type the child would choose to adopt in the future.

\subsection{Data Analysis}

Data wereanalyzed using SPSS programmer. To examine differences between two independent samples (i.e., gender, with or without acompanion animal), we conducted aT-test. Further, we appliedan F-test (Analysis of Variance ANOVA) to examine differences between more than two groups,such as three groups based onfathers' educational level. Finally, we conducted a Pearson test to examine the correlation between children's attitudes toward companion animals and reading stories about animals.

\section{Results}

\subsection{Children's Attitudes toward Companion Animals}

Table 1 showsthe means and standard deviations of the children's responses to the questionnaire items regarding their attitudes towardandexperiences with companion animals.The results indicate a statistically significant difference between children with and without companion animals at home. Children witha companion animal at homeexpressmore positiveattitudes toward companion animalsas compared withthose who donot. Thus, hypothesis 1 is confirmed. 


\begin{tabular}{|c|c|c|c|c|c|}
\hline & \multicolumn{2}{|c|}{$\begin{array}{c}\text { No Companion Animal } \\
\text { in The Home } \\
\text { (N=129) }\end{array}$} & $\begin{array}{c}\text { Companion Animal in } \\
\text { the Home } \\
\text { (N=134) }\end{array}$ & Sig \\
\hline $\begin{array}{c}\text { Children's attitudes toward companion } \\
\text { animals }\end{array}$ & 2.33 & 0.38 & 2.46 & 0.26 & 0.00 \\
\hline
\end{tabular}

Table 1: Attitudes toward Companion Animals Amongchildren with and without a Companion Animal at Home $\mathrm{T}=3.18 ; \mathrm{P}<001$

Table 2 shows attitudes according to grade. AT-testfoundno statistically significant difference between children's attitudes toward companion animals according to grade level.

\begin{tabular}{|c|c|c|c|c|c|}
\hline & \multicolumn{2}{|c|}{$\begin{array}{c}\text { Second Grade } \\
(\mathrm{N}=129)\end{array}$} & \multicolumn{2}{c|}{$\begin{array}{c}\text { First Grade } \\
(\mathrm{N}=134)\end{array}$} & Sig \\
\hline & mean & S.D. & mean & S.D. & \\
\hline $\begin{array}{c}\text { Children's } \\
\text { attitudes toward } \\
\text { companion } \\
\text { animals }\end{array}$ & 2.4 & .34 & 2.39 & .32 & .77 \\
\hline
\end{tabular}

Table 2: Children's Attitudes toward Companion Animals, by Grade in School $\mathrm{p}>0.05$

Table 3 showsthe children's attitudes toward companion animals according to gender. The difference in the boys'and girls'average scoresisnot statistically significant.

\begin{tabular}{|c|c|c|c|c|c|}
\hline & \multicolumn{2}{|c|}{$\begin{array}{c}\text { Girls } \\
\mathbf{( N = 1 3 5 )}\end{array}$} & \multicolumn{2}{c|}{$\begin{array}{c}\text { Boys } \\
\text { (N=132) }\end{array}$} & Sig \\
\hline & mean & S.D. & mean & S.D. & \\
\hline $\begin{array}{c}\text { Children's attitudes } \\
\text { toward companion } \\
\text { animals }\end{array}$ & 2.42 & 0.34 & 2.37 & 0.32 & 0.24 \\
\hline
\end{tabular}

Table 3: Children's Attitudes toward Companion Animals by Gender $\mathrm{P}>0.05$

$\mathrm{P}=\mathrm{N} . \mathrm{S}$

In order to examine whetherthe fathers' education level is related to a differences in children's attitudes, we conducted ANOVA test. The results are given in Table 4. There are no statistically significant differences in attitudes toward companion animals among children whose fathers completed middle school, high school, or higher education. Thus, fathers' level of education didnot affect their children's attitudes toward companion animals.

\begin{tabular}{|c|c|c|c|c|c|c|c|c|c|c|}
\hline & \multicolumn{2}{|c|}{$\begin{array}{c}\text { Middle school } \\
(\mathbf{N = 4 1 )}\end{array}$} & \multicolumn{2}{|c|}{$\begin{array}{c}\text { High school } \\
\mathbf{( N = 1 3 6 )}\end{array}$} & \multicolumn{2}{|c|}{$\begin{array}{c}\text { Higher education } \\
\mathbf{( N = 7 8 )}\end{array}$} & \multicolumn{2}{|c|}{$\begin{array}{c}\text { Other } \\
\mathbf{( N = 1 0 )}\end{array}$} & F & sig \\
\hline & mean & S.D. & mean & S.D. & mean & S.D. & $\begin{array}{c}\text { me } \\
\text { an }\end{array}$ & S.D. & & \\
\hline $\begin{array}{c}\text { Children's } \\
\text { attitudes toward } \\
\begin{array}{c}\text { companion } \\
\text { animals }\end{array}\end{array}$ & 2.39 & 0.31 & 2.41 & 0.33 & 2.40 & 0.35 & $\begin{array}{c}2.2 \\
9\end{array}$ & 0.25 & 0.3 & 0.77 \\
7 & & & & & & & & & \\
\hline
\end{tabular}

Table 4: Children's Attitudes toward Companion Animals, by

Fathers' Educational Level

$$
\mathrm{P}>0.05
$$

Table 5 showschildren's attitudes toward companion animals according to their mothers' education. Differences between the averages among children according totheir mothers' educational levelarenot significant. The mothers'level of education didnot affect their children's attitudes toward companion animals. 


\begin{tabular}{|c|c|c|c|c|c|c|c|c|c|c|}
\hline & \multicolumn{2}{|c|}{$\begin{array}{c}\text { Middle School } \\
\text { (N=29) }\end{array}$} & \multicolumn{2}{|c|}{$\begin{array}{c}\text { High School } \\
\mathbf{( N = 1 2 8 )}\end{array}$} & \multicolumn{2}{c|}{$\begin{array}{c}\text { Higher } \\
\text { Education } \\
\mathbf{( N = 1 0 0 )}\end{array}$} & \multicolumn{2}{c|}{$\begin{array}{c}\text { Other } \\
\mathbf{( N = 9 )}\end{array}$} & F & sig \\
\hline & Mean & S.D. & mean & S.D. & mean & S.D. & mean & S.D. & & \\
\hline $\begin{array}{c}\text { Children's attitudes } \\
\text { toward companion } \\
\text { animals }\end{array}$ & 2.34 & 0.41 & 2.39 & 0.34 & 2.43 & 0.28 & 2.30 & 0.27 & 0.87 & 0.45 \\
\hline
\end{tabular}

Table 5: Children's Attitudes toward Companion Animals, bymother's Educational Level $\mathrm{P}>0.05$

Table 6 showschildren's attitudes toward companion animals according to their family's socioeconomic status. There was no statistically significant difference between children's attitudes toward companion animals based on SES. Thus, socioeconomic status didnot affect children's attitudes toward companion animals.

\begin{tabular}{|c|c|c|c|c|c|c|c|c|}
\hline & \multicolumn{2}{|c|}{$\begin{array}{c}\text { Low SES } \\
(\mathbf{N = 3 3 )}\end{array}$} & \multicolumn{2}{c|}{$\begin{array}{c}\text { Medium SES } \\
\mathbf{( N = 1 2 5 )}\end{array}$} & \multicolumn{2}{c|}{$\begin{array}{c}\text { High SES } \\
\mathbf{( N = 1 0 9 )}\end{array}$} & F & sig \\
\hline & mean & S.D. & mean & S.D. & mean & S.D. & & \\
\hline $\begin{array}{c}\text { Children's attitudes } \\
\text { toward companion } \\
\text { animals }\end{array}$ & 2.29 & .40 & 2.40 & .32 & 2.42 & .31 & 2.42 & .09 \\
\hline
\end{tabular}

Table 6: Children's Attitudes toward Companion Animals, by Socioeconomic Status $\mathrm{P}>0.05$

\subsection{Impact of Reading Stories on Children's Attitudes toward Companion Animals}

In order to examine hypothesis $2 \mathrm{~b}$, a Pearson test was conducted. We found a strong and significant relation between children's attitudes toward companion animals and reading stories $(r=0.628, p<0.001)$ such that the more thatchildren read stories about animals, the more positive their stance toward companion animals. Thus, the second hypothesis is confirmed.

\subsection{Choice of Companion Animal and Child's Gender}

Dogs and cats were the most common companion animals for boys.However, among boys without a current companion animal, the choice for future adoptions shifted slightly to dogs and birds. Fish were among the least common choices for companion animals, both currently and as a future possibility. Among girls, the most common companion animals were cats and birds, and the least common were dogs and fish, both currently and as a future choice. Thus, the third hypothesis is not confirmed.

\section{Discussion}

This study validates our hypothesis that the more personal experience a child has with companion animals, the more positive his/ her stance toward them will be. External factors such as socioeconomic status, parents' education, and child's gender donot have a strongereffect on children's attitudes than personal experience. A statistically significant correlation isfound between children's attitudes toward companion animals and having companion animals at home. Children with a companion animal at home expressedmore positives attitude toward animals than those with no companion animal in the home (Table 1).

This finding confirms the conclusions of Prokop and Tunnicliffe's (2008) study in Slovenia on three groups of children aged 5-15 years exploring the effects of adopting companion animals on children's attitudes toward popular and unpopular animals. They also found that children who had companion animals at home expressed more positive attitudes and showed more knowledge about animals in general than those who did not have companion animals. The more frequently the children handled companion animals (on a scale of 1-3), the more their positivityincreased.Similarly, our finding is in line withthestudy by Prokop, Özel, and Usak (2009) among students from Slovenia and Turkey, which finds that the experience of caring for companion animals contributesto participants' positive attitude toward unpopular animals such as snakes.A group of 18- to 21-year-old students from Canada who, as children, had a dog, a cat or both as companion animals, showed less stress and better social skills than students who did not have childhood companion animals (Daly \& Morton, 2009). This finding further reinforces the importance of personal experience in creating benefits for children.

There isno statistically significant difference between children's attitudes toward companion animals by gender (Table 3). Similarly, Prokop and Tunnicliffe (2008) findno association between gender and attitudes toward or knowledge of companion animals among their study participants. Although they do not assess the number of companion animals owned by the participants, their finding strengthens our suggestion that there is no association between gender and attitudes toward or knowledge of companion animals. Our hypothesis regarding differences between type of companion animal and gender isnot validated. Choice of concurrent or future companion animals isnot found to be gender-dependent. Boys' and girls'companion animal choices did not differ significantly.

However, Prokop and Tunnicliffe's (2008) study finds that girls aged 10-15 years in Slovenia were guardians formore companion animals than boys were. Regarding the effects of adopting companion animals on children's attitudes 
toward popular and unpopular animals, theyfindthat girls took a more positive stance toward popular animals, such as rabbits and squirrels, and a less positive stance toward non-popular animals as compared to boys. Boys expressed more positive stances toward wolves than girls. A less positive attitude toward dangerous or disease-causing animals seems to be characteristic of girls.

In the study by Prokop and Tunnicliffe (2008), the most common companion animals in the category most relevant to our study (5- to 10-year-olds) were dogs, cats, birds, and poultry. In the study by Wells and Perrine (2001), $74 \%$ of the participants haddogs as companion animals, and only $34 \%$ hadcats as companion animals. In a study exploring visual acquaintance with animals and fear in 27 kindergarten-aged children (5-6 years old) in the Czech Republic, three common animal choices are dolphins, dogs and cats. The children stated that they love dogs and cats because they are beautiful and cats have velvety fur. No differences arefound between ages or genders (Kubiatko, 2012). These studies are relevant to our finding, in that theyindicatea universal type of choices amongchildren. However, these results differ from the study of Stekette et al. (2011) on the acquisition of companion animals by adults, which found that adult women prefer cats to dogs.

Girls' sensitivity to animals ismeasured in terms of grief at a companion animal's deathby Brown, Richards, and Wilson (1996) who find that girls are more apt to express sadness than boys. Israelis have been found to be one of the nationalities who are likely to cry when a companion animal dies(Williams \& Morris, 1996).

According to the findings shown in Tables 4-6, there isno significant association between positive attitudes toward companion animals and parents' education, or socioeconomic status. According to Prokop and Tunnicliffe (2008), the probability of having companion animals in the home is higheramongchildren whose parents have a higher level of education. In our research, we did not measure the association between having companion animals and parents' education, but we did measure the connection between positive attitudes toward companion animals and parents' education. The finding of SES not being significantly associated with children's attitudes toward companion animals might be due to the fact that this factor is regarded as an external effect.Only personal experienceswerefound to affect the children's attitudes. Familiesin the Arab sector in Israel do not tend to spend significantamounts of money on companion animal paraphernalia, and most of the food they give to the animals consists of leftovers from family meals.Thus, a high SES is not a prerequisite to owning a companion animal.Our second hypothesis isalso confirmed: reading stories about animals represents an aspect of personal experience, and children who read stories about animals have more positive attitudes toward companion animals compared to those who read fewer or no such stories. In general, these stories present animals as likeable, positive characters.Readers, especially children, feel empathy toward them. Studies indicate that people who show empathy toward others and are open, pleasant, and self-aware, tend toshow more positive attitudes toward companion animals as compared to individuals who do not have these characteristics (Erlanger \&Tsytsarev, 2012).

Some studies find that the transition from the imaginary world of animals portrayed in stories or films to the real world may beproblematic. Children regard animals in stories and films differently from real animals. In the stories,animalsare heroes. They talk, have superpowers, and fall in love. This may affect the child's comprehension of the reality of animals. It may cause problems and result in suffering for companion animals that do not meet the child's expectations, which arebased onfantasy or the media (Anderson \& Henderson, 2005). In this study, we did not consider films or other elements of the imagination as variables. The questions regarding reading stories were general and did not touch on the details associated with the child's imaginary world.

\section{Conclusion}

This study exploresthree hypotheses. The first predicts a significant association between children's positive attitudes toward companion animals and their personal experience with them. The second predicts a significant connection between reading stories about animals and a positive attitude toward companion animals. The third predictsthat the type of companion animal owned or selected for future guardianship would be related tothe child's gender.

Our survey of 267 Arab children from the northern and Triangle areas of Israel confirmsthese hypotheses.A statistically significant connection was found between raising companion animals at home and a positive attitude toward them. Children withcompanion animals at home expresseda more positive stance toward animals than those withoutcompanion animals in the home. This indicates the contribution of personal experience in raising companion animals to creating a positive stance toward animals in general and companion animals in particular.

In addition, reading stories about animals creates a type of personal and emotional experience in the child's mind. Children who read more stories about animals expressedmore positive attitudes toward animals than those who read fewer or no such stories.

Choice of companion animalisnot dependenton the child's gender. Dogs and cats were the most common companion animals for both. Boys said they prefer dogs, cats, and birds, while girls said they prefer cats and birds.

This research was conducted in Arab society in Israel. Future researchcan extend exploration of this topic. For example, there could be a comparison between attitudes among children in Arab and Jewish society in Israel, or the study may be extended to other cultures. Futurestudies may examine children at other ages or levels of schooling. Further, future studies may examine if positive attitudes toward companion animals decrease violent behavior, specifically among adolescents. 


\section{References}

i. Anderson, M. V., \& Henderson, A. J. Z. (2005). Pernicious portrayals: The impact of children's attachment to animals of fiction in animals of fact. Society \& Animals, 13(4), 297-314.

ii. Archer,J. (1997). Why do people love their pets? Evolution and Human Behavior, 18, 237-259.

iii. Binfet, J. T., \&Passmore, H. A. (2016). Hounds and homesickness: The effects of an animal-assisted therapeutic intervention for first-year university students. Anthrozoös, 29(3), 441-454.

iv. Beverland, M. B., Farrelly, F., \&Ching Lim, E. A. (2007). Exploring the dark side of pet ownership: Status and control-based pet consumption. Journal of Business Research, 61, 490-496.

v. Brown, B. H., Richards, H. C., \& Wilson, C. A. (1996). Pet bonding and pet bereavement among adolescents. Journal of Counseling \& Development, 74, 505-509.

vi. Daly, B., \& Morton, L. L. (2009).Empathic differences in adults as a function of childhood and adult pet ownership and pet type. Anthrozoös, 22(4), 371-382.

vii. Erlanger, A. C. E., \&Tsytsarev, S. V. (2012). The relationship between empathy and personality in undergraduate students' attitudes toward nonhuman animals. Society \& Animals, 20, 21-38.

viii. Jagoe, A., \&Serpell, J. (1996).Owner characteristics and interactions and the prevalence of canine behaviour problems. Applied Animal Behavior Science, 47, 31-42.

ix. Kubiatko, M. (2012).Kindergarten children's perception of animals focusing on the look and fear of animals. Educational Sciences: Theory andPractice, 12(4),3181-3186.

x. Kurdek, L. A. (2009). Pet dogs as attachment figures for adult owners. Journal of Family Psychology, 23(4), 439446.

xi. Lago, D., Kafer, R., Delaney, M., \&Connel, C. (1988).Assessment of favorable attitudes towards pets: Development and preliminary validation of self- report pet relationship scales. Anthrozoös, 1, 240-254.

xii. McConnell, A. R., \& Brown, C. M. (2011). Friends with benefits: On the positive consequences of pet ownership. Journal of Personality and Social Psychology, 101(6), 1239-1252.

xiii. Morley, C., \&Fook, J. (2005).The importance of pet loss and some implications for services.Mortality, 10(2), 127143.

xiv. Pattnaik, J. (2004). On behalf of their animal friends: Involving children in animal advocacy. Childhood Education, 81(2), 95-100.

xv. Prokop, P., \&Tunnicliffe, S. D. (2008). "Disgusting "animals: Primary school children's attitudes and myths of bats and spiders. Eurasia Journal of Mathematics, Science \& Technology Education, 4, 87-97.

xvi. Prokop, P., Özel, M., \&Usak, M. (2009). Cross-cultural comparison of students' attitudes toward snakes. Society \& Animals, 17(3), 224-240.

xvii. Prokop, P., \&Fančovičová, J. (2011). The effect of owning animals on perceived vulnerability to, and avoidance of, parasitic diseases in humans. Journal of Individual Differences, 32(3), 129-136.

xviii. Raupp, C. D. (1999). Treasuring, trashing or terrorizing: Adult outcomes of childhood socialization about companion animals. Society and Animals, 7(2), 141-159.

xix. Serpell, J. (1996). Evidence for an association between pet behaviour and owner attachment levels. Applied Animal Behaviour Science, 47, 49-60.

xx. Stallones, L. (1994). Pet loss and mental health. Anthrozoös, 7, 43-54.

xxi. Stekette, G., Gibson, A., Frost, R. O., Alabiso, J., Arluke, A., \&Patronek, G. (2011). Characteristics and antecedents of people who hoard animals: An exploratory comparative interview study. Review of General Psychology, 15(2), 114-124.

xxii. Van Houtte, B. A. \& Jarvis, P. (1995). The role of pets in preadolescent psychosocial development. Journal of Applied Developmental Psychology, 16, 463-479.

xxiii. Veldkamp, E. (2009). The emergence of "pets as family "and the socio-historical development of pet funerals in Japan. Anthrozoös, 22(4), 333-346.

xxiv. Wells, D. L. (2009).The effects of animals on human health and well-being. Journal of Social Issues, 65(3), 523543.

xxv. Wells, M., \& Perrine, R. (2001). Critters in the cube farm: Perceived psychological and organizational effects of pets in the workplace. Journal of Occupational Health Psychology, 6(1), 81-87.

xxvi. Williams, D. G., \& Morris, G. H. (1996). Crying, weeping or tearfulness in British and Israeli adults.British Journal of Psychology, 87, 479-505.

xxvii. Zasloff, R. L., \&Hart, L. A.(2000). Animals in elementary school education in California. Journal of Applied Animal Welfare Science, 2(4), 347-357. 


\section{Appendix}

Questionnaire Items on Attitudes toward Companion Animals

- A companion animal brings joy and delight to the house.

- A companion animal ruins the house's belongings.

- A companion animal is useful for the house's residents.

- Animals' normal habitat is either in nature or zoos, not houses.

- A companion animal is a friend of his/ herguardian.

- Raising companion animals is a great delight.

- Companion animals are dirty and spread diseases to children.

- Raising companion animals is a waste of time.

- Raising companion animals is financially expensive.

- Keeping companion animals enhances children's feelings of sympathy.

- Keeping companion animals enhances children's sense of responsibility.

- Having companion animals at home could be harmful for children.

- I treat my family members and companion animal equally.

- When having a companion animal, we don't feel lonely.

- When we feel upset, we can talk to ourcompanion animal and be comforted.

- Keeping companion animals helps me explore scientific facts about them.

- I punish my companion animal when I get angry.

- Companion animals have feelings and I respect them.

- I can understand companion animals and meet their needs.

- I like treating my companion animal nicely.

- Keeping companion animals enhances thinkingabilities.

- Keeping companion animals teaches me facts about animals' world.

- Wereyou inspired by stories to love a specific type of companion animal?

- Wereyou influenced by stories to keep a companion animal at your house?

- Wereyou motivated by stories to be sympathetic and caring toward companion animals? 